See discussions, stats, and author profiles for this publication at: https://www.researchgate.net/publication/311954642

\title{
Problematic topics in first-year mathematics: lecturer and student views
}

Article in International Journal of Mathematical Education · July 2017

DOI: 10.1080/0020739X.2016.1272142

\section{CITATIONS}

2

4 authors, including:

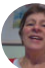

Caitríona Ní Shé

Dublin City University

11 PUBLICATIONS 4 CITATIONS

SEE PROFILE

Eabhnat Ní Fhloinn

Dublin City University

49 PUBLICATIONS 136 CITATIONS

SEE PROFILE
83

Ciarán Mac an Bhairc

National University of Ireland, Maynooth

27 PUBLICATIONS 117 CITATIONS

SEE PROFILE

Some of the authors of this publication are also working on these related projects:

Assessment for Learning Resources for First Year Undergraduate Mathematics Modules View project 


\section{Problematic topics in first-year mathematics: lecturer and student views}

\section{Caitríona Ní Shé, Ciarán Mac an Bhaird, Eabhnat Ní Fhloinn \& Ann O'Shea}

To cite this article: Caitríona Ní Shé, Ciarán Mac an Bhaird, Eabhnat Ní Fhloinn \& Ann O'Shea (2016): Problematic topics in first-year mathematics: lecturer and student views, International Journal of Mathematical Education in Science and Technology, DOI: 10.1080/0020739X.2016.1272142

To link to this article: http://dx.doi.org/10.1080/0020739X.2016.1272142

\section{曲 Published online: 28 Dec 2016.}

\section{Submit your article to this journal ๘}

Щ Article views: 38

Q View related articles ¿

View Crossmark data $\asymp$ 


\title{
Problematic topics in first-year mathematics: lecturer and student views
}

\author{
Caitríona Ní Shé $\odot^{\mathrm{a}, \mathrm{b}}$, Ciarán Mac an Bhaird ${ }^{\mathrm{b}}$, Eabhnat Ní Fhloinn $\oplus^{\mathrm{a}}$ and Ann O’Sheab \\ ${ }^{a}$ School of Mathematical Sciences, Dublin City University, Dublin, Ireland; ${ }^{\mathrm{b}}$ Department of Mathematics and \\ Statistics, Maynooth University, Co. Kildare, Ireland
}

\begin{abstract}
In this paper we report on the outcomes of two surveys carried out in higher education institutions of Ireland; one of students attending first-year undergraduate non-specialist mathematics modules and another of their lecturers. The surveys aimed to identify the topics that these students found difficult, whether they had most difficulty with the concepts or procedures involved in the topics, and the resources they used to overcome these difficulties. In this paper we focus on the mathematical concepts and procedures that students found most difficult. While there was agreement between students and lecturers on certain problematic topics, this was not uniform across all topics, and students rated their conceptual understanding higher than their ability to do questions, in contrast to lecturers' opinions.
\end{abstract}

\section{ARTICLE HISTORY}

Received 5 September 2016

\section{KEYWORDS}

Problematic topics; lecturer views; student views; mathematical concepts; mathematical procedures; higher education

\section{SUBJECT}

CLASSIFICATION CODES 9702; 97C99; 97 U9

\section{Introduction}

It is generally agreed that students have problems transitioning from mathematics at secondary level to mathematics in higher education and that significant numbers of students have not mastered the basic mathematical skills required for first-year undergraduate mathematics modules [1-3]. A number of studies have identified particular topics that prove problematic for students [4-7]. However, from the research carried out to date, it is not clear if students have difficulties with both the concepts and procedures involved. Additionally there is little evidence to suggest that students can identify these problems themselves and hence seek to redress them.

As part of a larger project on the development of technology-enhanced formativeassessment resources to support teaching and learning in first-year undergraduate nonspecialist mathematics modules, lecturers and students in higher education institutions (HEIs) in Ireland were surveyed. The purpose of the surveys was twofold: to identify mathematical topics, concepts and procedures that are problematic for first-year undergraduate students in HEIs; and to determine the resources currently in use by students, those recommended by lecturers to help overcome these difficulties and suggestions for new resources. This paper presents findings from the former; the latter will be discussed in a subsequent paper [8]. The research questions addressed in this paper are: 
(1) What topics do students attending first-year service mathematics modules deem to be problematic?

(2) Is it the concept or the procedure related to the topic that students identify as causing the most difficulty?

(3) What concepts and procedures do lecturers identify as problematic for their firstyear service mathematics students?

\section{Background}

This project focuses on the period of transition from secondary to higher education and the requirement for students to have an understanding of basic mathematical concepts and procedures in order to succeed in first-year undergraduate mathematics modules. The literature that follows examines transition and mathematical understanding in this context, after providing a brief overview of the Irish higher education system.

\subsection{Higher education in Ireland}

Higher level education in the Republic of Ireland is primarily provided by $21 \mathrm{HEIs}$, there are seven universities and 14 institutes of technology (IoTs). Students principally gain access to HEIs based on their results in the state examination, called the Leaving Certificate (LC). Mathematics in the LC is offered at three different levels; Higher Level (HL), Ordinary Level (OL) and Foundation Level (FL) [9].

\subsection{Mathematics during transition to higher education}

Clark and Lovric [10] identified the transition to mathematics in higher education as a 'rite of passage' where students move from one set of practices and beliefs formed at secondary to a new set in higher education. Guedet [11] identified the difference in teaching methods between secondary and higher education as being partly responsible for students' difficulties in transitioning, suggesting that appropriate online resources may be helpful in developing students' autonomy during this transition.

As a result of the widening of access to higher education $[2,12,13]$ the range of mathematical abilities demonstrated by incoming first-year undergraduate students has increased. This, coupled with the difficulties associated with the transition to mathematics in higher education, has resulted in many students being inadequately prepared for mathematics.

A number of studies in the UK $[2,14]$ and in Australia $[4,13,15]$ found that students in first-year undergraduate programmes demonstrated a lack of understanding of some of the basic mathematical concepts required. Tariq [16] conducted a study of 326 first-year biosciences students' mathematical ability from seven different institutions in the UK and found that students were better at mathematical calculations than word problems, suggesting that they lacked conceptual understanding of mathematics.

A study was carried out in the University of Southern Queensland (USQ) in Australia of student and lecturer perceptions about student preparedness for the mathematical content required in first-year undergraduate courses. While students were confident that they were adequately prepared, many lecturers considered that students had poor skills and lecturers 
had to adjust their courses accordingly [5]. The students in this study differed from the normal cohort in Ireland as over $80 \%$ were not recent school leavers.

Huidobro et al. [7] investigated the mathematical background of over 1000 students and 20 of their lecturers attending first-year engineering in the University of Oviedo in Spain. Students were reasonably confident in their mathematical skills in contrast to their lecturers who were less confident in their students' ability. Lecturers and students concurred that secondary school had not prepared students adequately for the mathematics they encountered.

A number of common areas were identified as problematic across these studies including basic algebra, arithmetic, logs, statistics, calculus and functions. Tariq [14], Loughlin et al. [13] and Watters and Watters [15] all found that first-year bioscience undergraduates had particular problems understanding and using logs.

\subsection{Mathematical understanding}

Students' conceptual understanding and procedural skills were assessed in a study undertaken by Engelbrecht, Harding and Potgieter [17] in the University of Pretoria in South Africa. They found that students did not perform better in procedural problems over conceptual ones and they were more confident in their ability to do conceptual rather than procedural problems. The authors suggested that this may be attributed to a new approach that had been taken for the teaching of this course where conceptual thinking was cultivated. However, in a further study, Engelbrecht, Bergsten and Kagesten [18] found that engineering students often attempted to solve conceptual problems using procedural techniques. Mahir [19] examined students $(n=62)$ who had just completed first-year Calculus courses in Turkey on their conceptual and procedural knowledge of integration and concurred with Engelbrecht et al. [18] that students who possessed adequate conceptual knowledge could also perform the procedures. Similarly, Mahir [19] found that most students did not possess a conceptual understanding of integration and were inclined to use routine manipulations and procedures rather than a conceptual approach to solving integration problems.

\section{Methodology}

Two surveys were carried out at the start of this project: one of students attending first-year undergraduate mathematics modules in the four HEIs involved and the other of lecturers teaching first-year undergraduate mathematics in all of the HEIs on the island of Ireland. The questions were developed by the nine members of the project team in the four HEIs. ${ }^{1}$ The mathematical topics selected were all on the OL LC curriculum and were mostly on the first-year undergraduate curriculum in the four HEIs involved and are similar to those used by Dalby et al. [4].

The questionnaire was piloted on different groups of students, the results analyzed and the questionnaire adjusted accordingly. The final questionnaire had 46 Likert item questions followed by seven open-ended questions, of which two are relevant to this paper. The Likert items concerned the mathematical topics selected by the project team. Students were asked to rate their ability to (a) 'Understand' the ideas involved and (b) 'Do' the questions, on a 5-point Likert scale: Strongly Agree (SA), Agree (A), Neutral (N), Disagree (D) and Strongly Disagree (SD). The open questions asked which topics caused the students most 
difficulty and whether it was the 'Ideas' or 'Methods' that caused the difficulty. The terms 'Understand', 'Do', 'Ideas' and 'Methods' were used in the questionnaire as students may not have understood the terminology of 'concepts' and 'procedures'. There were five questions at the beginning of the survey that asked students about their background. Appendix A contains a copy of the student questionnaire.

A total of 460 students completed the student survey in the spring of 2015. The students were registered in a range of different undergraduate programmes: Arts, Applied Sciences, Computing, Engineering and Business. Most were just finishing their first year in higher education. A small number (about 20) were at the end of their second year. Teaching methods varied across the different institutions and disciplines. However, all students were exposed to elements of direct instruction and problem solving and both concepts and procedures were part of the curriculum.

The breakdown by student background category is shown in Table 1. As mentioned earlier, entry requirements tend to be lower for the IoTs; hence the percentage of students who had taken OL mathematics in both AIT (75\%) and DkIT (64\%) was far higher than in DCU (13\%) and MU (13\%).

The Likert survey data was analyzed in Excel and SPSS, using chi-squared and Wilcoxon Signed Rank tests. The open-ended questions were analyzed in Nvivo, using a General Inductive Analysis (GIA) [20] approach to analysis of the data. The raw data was examined for the most frequently mentioned topics; categories were created based on these and on the research objectives. The data was then coded into the relevant categories which were continuously refined throughout the analysis.

The lecturer questionnaire was designed to enable a comparison between the lecturer and student responses and was piloted in the four HEIs involved in the project. The final questionnaire consisted of 10 open-ended questions, five of which are relevant to this paper: three background questions, one question that asked what concepts their students found difficult and one on what procedures and tasks caused most difficulty. Lecturers, in HEIs across the island of Ireland, were asked to complete the questionnaire via a Google form.

Table 1. Student background data $(n=460)$.

\begin{tabular}{|c|c|}
\hline Student background category & Number (\% of overall respondents in that category) \\
\hline \multicolumn{2}{|c|}{ Student gender } \\
\hline Male & $293(65 \%)$ \\
\hline Female & $160(35 \%)$ \\
\hline \multicolumn{2}{|c|}{ Student category } \\
\hline Non-mature & $368(84 \%)$ \\
\hline Mature & $69(16 \%)$ \\
\hline \multicolumn{2}{|c|}{ Prior mathematics level } \\
\hline Higher level (LC) & $282(64 \%)$ \\
\hline Ordinary level (LC) & $142(32 \%)$ \\
\hline Foundation level (LC) & $5(1 \%)$ \\
\hline Did not take mathematics (LC) & $15(3 \%)$ \\
\hline $\mathrm{HEl}$ & Total student numbers \\
\hline Dublin City University (DCU) & 204 \\
\hline Maynooth University (MU) & 107 \\
\hline Dundalk Institute of Technology (DkIT) & 101 \\
\hline Athlone Institute of Technology (AIT) & 48 \\
\hline
\end{tabular}


None of the nine lecturers involved in the project team, nor those involved in the questionnaire pilot, completed the final questionnaire. There were 32 responses, 16 from IoTs and 16 from universities. Sixteen HEIs were represented, 9 IoTs and 7 universities, including two from Northern Ireland. All those surveyed were involved in teaching first-year service mathematics modules and/or providing mathematics support. The responses were coded using Nvivo, using the same methodology as for the students' responses. Appendix B contains a copy of the questions asked.

\section{Results}

In this section, we will first consider the results of the student Likert questions before moving on to report on the topics identified as most difficult by students and lecturers, as well as those identified as easiest by students.

\subsection{Results from student survey Likert questions}

Figure 1 shows the percentage of student responses, per Likert scale, for each question. The majority of students were positive (SA or A) about their ability to (a) 'Understand' and (b) 'Do' the question types, with only eight questions where greater than $10 \%$ of students responded with either D or SD. These were: Q5 Logs - using the laws of logarithms to simplify expressions; Q6 Logs - using the connections between logs and exponents; Q13 - finding limits of functions using graphs; Q14 - finding limits of functions using rules of limits; Q16 - deciding whether a function is continuous or not; Q21 - finding stationary points; Q22 - optimization (max/min) word problems; and Q23 - graph sketching using derivatives.

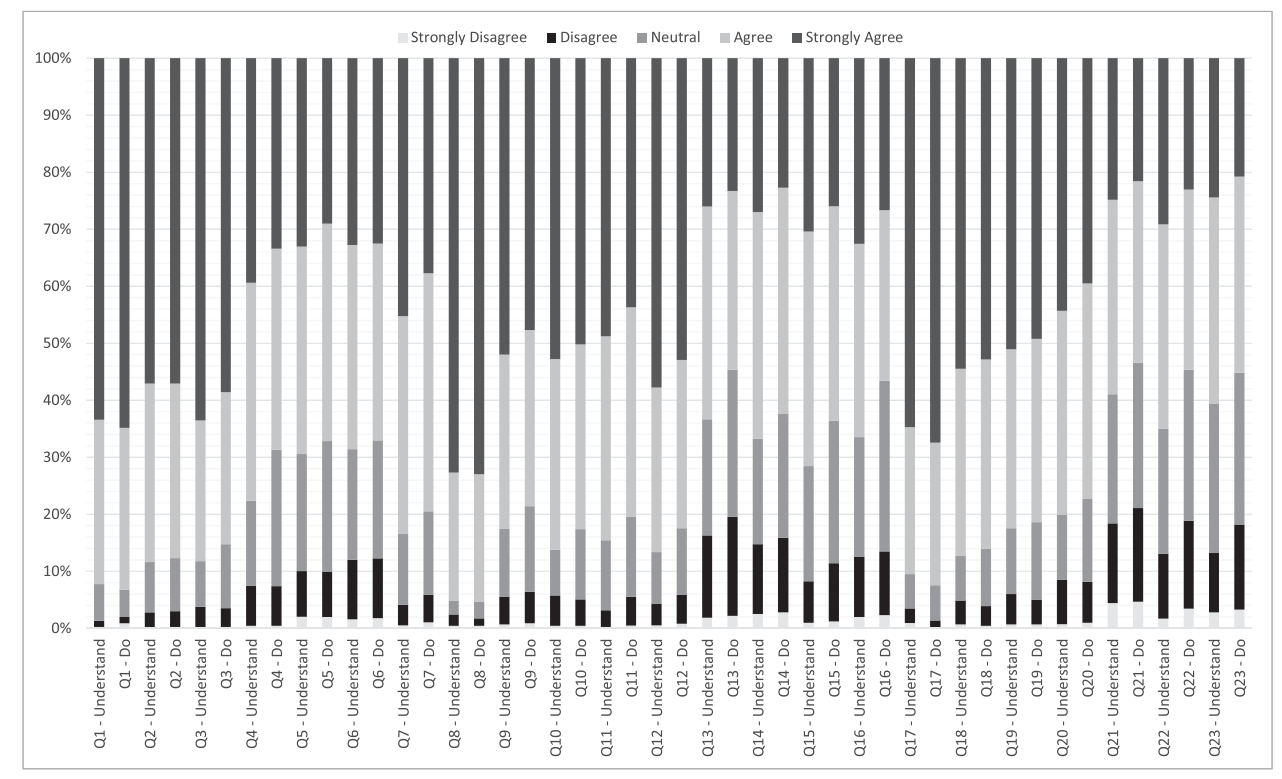

Figure 1. Percentage of student responses, per Likert scale, for each Likert question in the survey. ( $n=$ 460 , this was the maximum number of responses. All students did not respond to all of the questions.) 


\subsubsection{Ordinary and higher level}

Students who had taken HL mathematics at LC were significantly less likely to indicate that they had problems than those students who had taken OL (chi-squared tests comparing the total number of HL and OL student responses to each of the Likert scales across all the questions, $p<0.00001$ in each case). No statistically significant differences between responses were found for gender or mature student status. The questions with which OL students perceived they had most difficulty were the same eight questions listed in the previous paragraph, with at least $20 \%$ choosing $\mathrm{D}$ or SD. There were no question types where more than $20 \%$ of students who had taken HL mathematics responded in this way.

\subsection{2. 'Understand' and 'Do'}

One aim of the survey was to determine if students perceived that they had a different ability to 'Understand' (concept) or 'Do' (procedure) a particular question type. A statistically significant difference (Wilcoxon signed rank test, $p<0.01$ ) was found between 'Understand' and 'Do' in 17 of the 23 questions. In all but one of these, students perceived that they could 'Understand' better than 'Do' the question types. Q17 refers to basic differentiation and students perceived that they could 'Do' better than 'Understand' this question.

The following questions showed no significant difference between students' ranking of how well they could 'Understand' versus 'Do' them: Q1 Systems of Linear Equations, 2 variables; Q2 Systems of Linear Equations, 3 variables; Q6 Using the connections between logs and exponents; Q8 Solving quadratic equations; Q18 Differentiation: the product rule; and Q19 Differentiation: the quotient rule.

\subsection{Difficult topics, concepts and procedures}

Both the student and lecturer surveys asked which mathematical topics caused the most difficulty and sought specific comments on the nature of the difficulties involved for students.

\subsubsection{Student responses on 'topics causing difficulty'}

In addition to naming the topics that caused them most difficulty, students were also asked whether it was the 'Ideas' (concepts) or 'Methods' (procedures) involved that made the topic difficult. There were 414 student responses to this open-ended question, with some students making comments that fell under more than one topic area. These responses, coded according to the most commonly reported topics, are shown in Figure 2.

(As the topic 'logs, indices and exponents' appears frequently in the paper, it will be referred to as 'logs and powers' from here on.) There were a small number of students who reported problems with topics such as matrices, vectors and algebra.

Of the 414 respondents to this question, 390 provided their LC Mathematics level: 251 had taken HL, $134 \mathrm{OL}$ and $5 \mathrm{FL}$. This breakdown by prior mathematics level is in line with the breakdown in the survey as a whole (see paragraph above Table 1). The topics shown in Figure 2 were re-analyzed by prior mathematical level and the results are shown in Figure 3.

Chi-squared tests were conducted to compare the total percentage of HL versus OL students who identified each topic area as problematic. These showed a statistically significant difference in relation to logs and powers (chi-squared test, $p=0.001$ ) and integration 


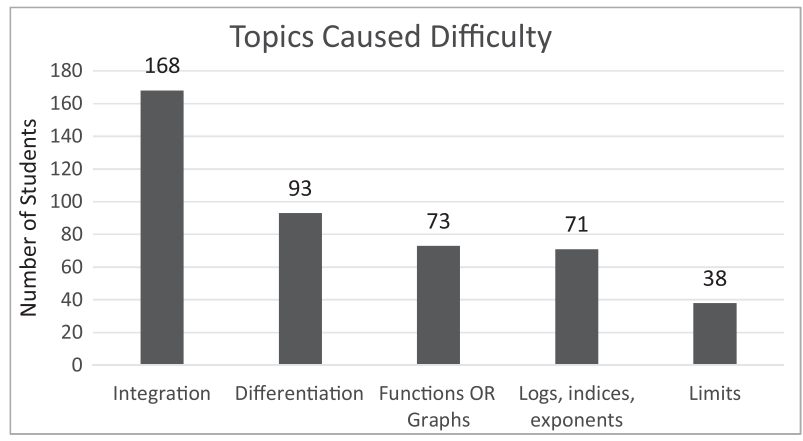

Figure 2. Number of students who named these topics as a 'topic causing difficulty'in the open questions of the survey $(n=414)$.

(chi-squared test, $p=0.027$ ). OL students were more likely to identify logs and powers as problematic, while HL students were more likely to mention integration in this context.

Students were asked whether it was the 'Ideas' or the 'Methods' involved that made topics difficult. One hundred and thirty-four of the 414 responses to the open question on 'topics causing difficulty' referred to 'Ideas' and 'Methods'. The number of responses referring to 'Ideas' and/or 'Methods' per topic is shown in Table 2. Different students are represented by $S$ and a randomly assigned number.

\subsubsection{Lecturer responses on concepts and procedures causing difficulty}

There were two questions which asked lecturers to identify difficulties students have in first year; the first question asked lecturers to name the concepts and the second the procedures and tasks that their students find difficult. Figures 4 and 5 show the most common concepts and procedures identified by the lecturers, recall that these were open questions and lecturers were free to give more than one answer.

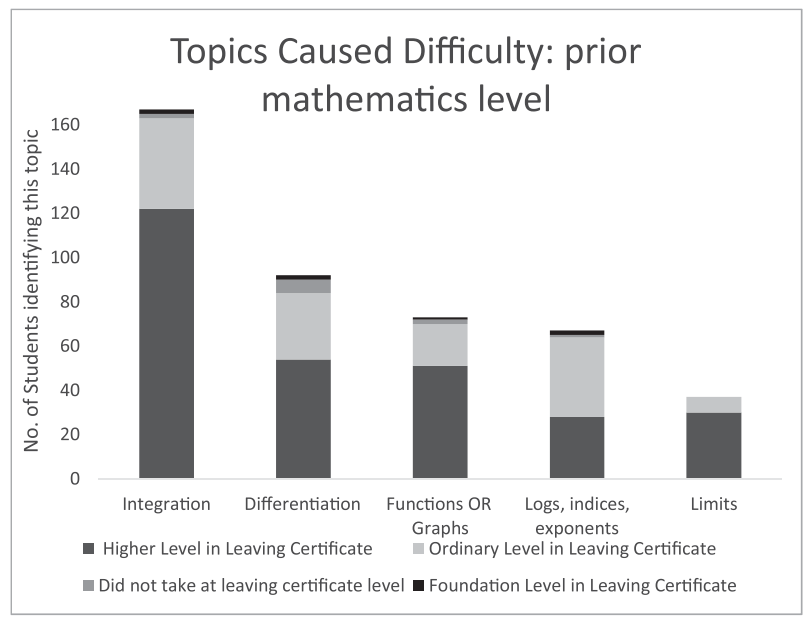

Figure 3. Number of students who identified the topic as a 'topic causing difficulty' by Leaving Certificate Mathematics level. 
Table 2. Number of students responses per topic referring to 'Methods' and 'Ideas' ( $n=134)$.

\begin{tabular}{|c|c|c|c|c|}
\hline Topic (total number) & Both & Method & Ideas & Sample response \\
\hline $\begin{array}{l}\text { Integration nd } \\
\quad \text { differentiation (77) }\end{array}$ & 10 & 45 & 22 & ...idea was fine but methods are a lot to deal with (S409) \\
\hline $\begin{array}{l}\text { Functions and } \\
\text { graphing (18) }\end{array}$ & 7 & 4 & 7 & $\begin{array}{l}\text { Ilearn the method of doing the question but do not } \\
\text { understand why ... (S59) }\end{array}$ \\
\hline Logs (18) & 7 & 5 & 6 & $\begin{array}{l}\text { always found them difficult to do but if I learn the methods } \\
\text { and rules I can do them (S366) }\end{array}$ \\
\hline Algebra (10) & 4 & 5 & 1 & $\begin{array}{l}\text {... mostly the ideas involved ... made topic difficult. I just } \\
\text { couldn't get my head around questions or what I was } \\
\text { being asked. (S95) }\end{array}$ \\
\hline Limits (10) & 6 & 3 & 1 & $\begin{array}{l}\text { The ideas involved ... made it difficult. The methods ... are } \\
\text { also difficult (S18) }\end{array}$ \\
\hline Matrices (8) & 4 & 2 & 2 & $\begin{array}{l}\text { methods are understandable however the ideas involved } \\
\text { were difficult/unclear (S26) }\end{array}$ \\
\hline Optimization (8) & 5 & 1 & 2 & $\begin{array}{l}\text { ideas ... were what I found most difficult ... found it hard to } \\
\text { visualise the question well enough ...to answer, or to } \\
\text { know where to begin .... (S56) }\end{array}$ \\
\hline $\begin{array}{l}\text { Vectors and complex } \\
\text { numbers (5) }\end{array}$ & 2 & 3 & 0 & methods seemed to over-complicate subject matter (S272) \\
\hline
\end{tabular}

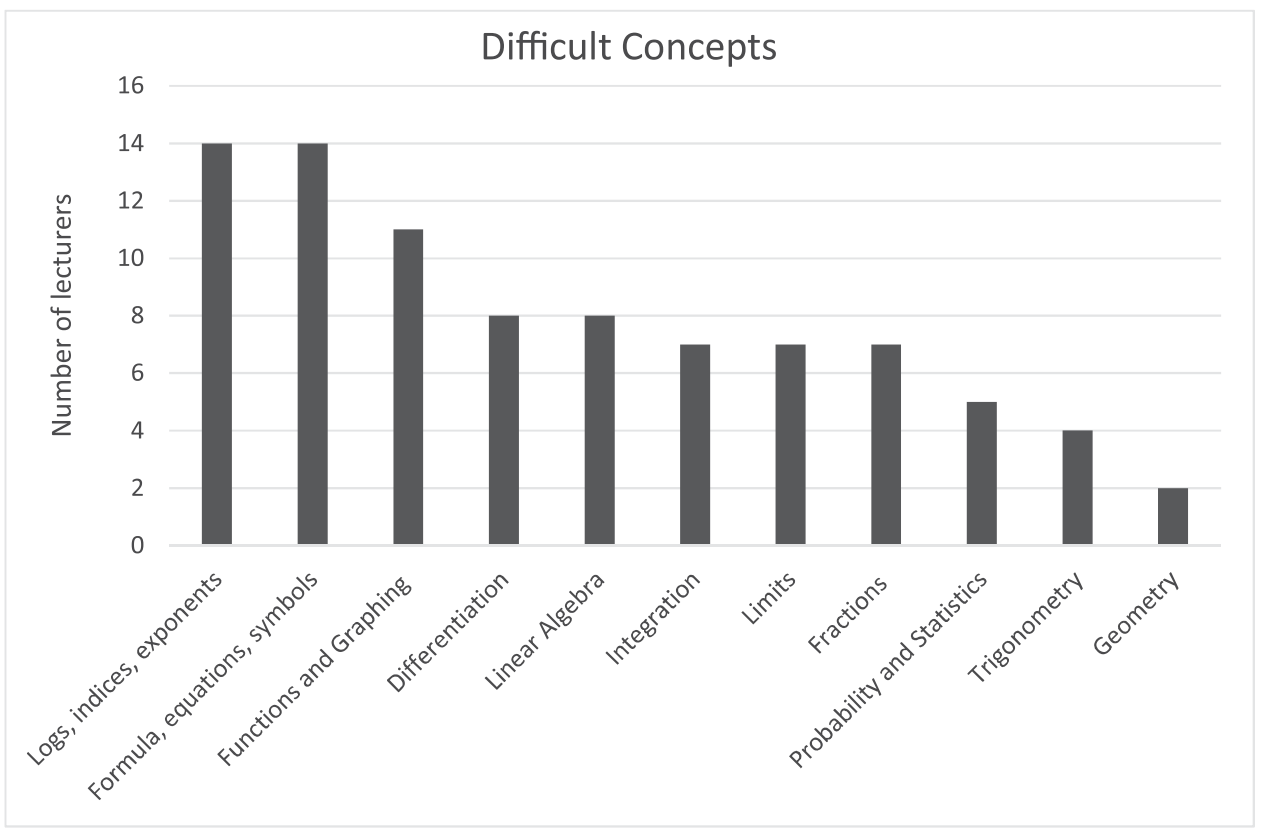

Figure 4. Number of lecturers who named the topic as a difficult concept in the open response questions in the survey $(n=32)$.

Sample comments for some of these topics are shown in Table 3. Different lecturers are labelled by $\mathrm{L}$ and a randomly assigned number.

\subsection{Easiest topics}

In addition to being asked about topics they found difficult, students were also asked which topics they found easiest in first-year mathematics. Students could give more than one answer and Figure 6 shows the breakdown of responses. 


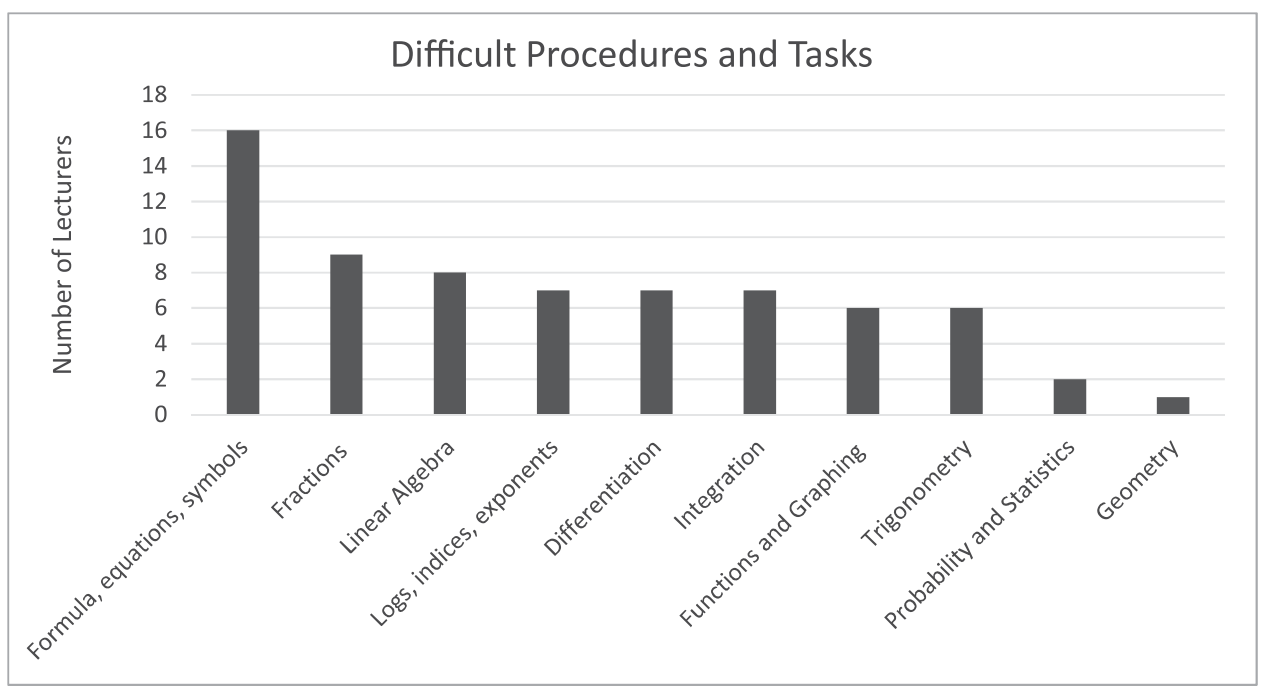

Figure 5. Number of lecturers who named the topic as a difficult procedure or task in the open response questions in the survey $(n=32)$.

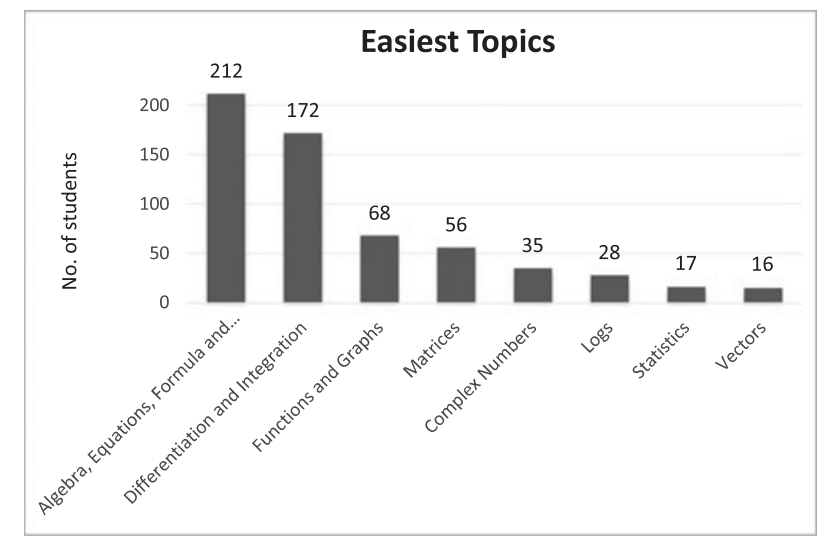

Figure 6. The number of students who identified the topic as an 'Easiest Topics' in the open response questions in the survey $(n=407)$.

Most of the 'Easiest Topics' identified by students were also identified as 'topics causing difficulty' by other students: for example, over $53 \%$ of students identified integration and/or differentiation as a topic that caused them difficulty. Statistics was the only topic that was not mentioned as one of the 'topics causing difficulty'.

In general, students were inclined to simply list the topics they found easy, only occasionally qualifying the remark with a reason. For example, one student found quadratic equations and maximum and minimum easy as they were '... topics which could be related to real world applications' (S326), while another student found the manipulation of formulae easy as '... it correlated with leaving certificate mathematics' (S275). 
Table 3. Sample Lecturer responses on difficult concepts and procedures $(n=32)$.

\begin{tabular}{|c|c|c|c|c|}
\hline \multirow[b]{2}{*}{ Category } & \multicolumn{2}{|r|}{ Concept responses } & \multicolumn{2}{|r|}{ Procedures responses } \\
\hline & $\#$ & Sample responses & $\#$ & Sample responses \\
\hline $\begin{array}{l}\text { Logs, indices and } \\
\text { exponents }\end{array}$ & 14 & $\begin{array}{l}\text { once the }[y] \text {... understood } \\
\text { concept of adding indices was } \\
\text { the same as multiplication of } \\
\text {... numbers, their engagement } \\
\text {... increased (L13) }\end{array}$ & 7 & $\begin{array}{l}\text { e.g. } \log (A+B) \text { expanded wrongly as } \\
\quad \log A+\log B .(\mathrm{L} 19)\end{array}$ \\
\hline $\begin{array}{l}\text { Formula equations } \\
\text { and symbols }\end{array}$ & 14 & $\begin{array}{l}\text { misuse symbols (...thinking } \\
\text { equals sign doesn't have to } \\
\text { mean ... both sides are equal } \\
\text { but it is more an assignment } \\
\text { operator) (L10) }\end{array}$ & 16 & $\begin{array}{l}\text { using brackets correctly, rules of } \\
\text { precedence (L11) }\end{array}$ \\
\hline $\begin{array}{l}\text { Functions and } \\
\text { graphing }\end{array}$ & 11 & $\begin{array}{l}\text { concepts of domain and range of } \\
\text { functions (L25) }\end{array}$ & 6 & $\begin{array}{l}\text { struggled with compositions of } \\
\text { functions (L25) }\end{array}$ \\
\hline differentiation & 8 & $\begin{array}{l}\text { chain rule, substitution in calculus } \\
\text { (L3) }\end{array}$ & 7 & $\begin{array}{l}\text { cannot distinguish between product, } \\
\text { quotient \& function of function } \\
\text { (L8) }\end{array}$ \\
\hline Integration & 7 & $\begin{array}{l}\text { Applications and problem solving } \\
\text { - e.g. when to differentiate, } \\
\text { when to integrate? (L27) }\end{array}$ & 7 & $\begin{array}{l}\text { Mixing up rules for differentiation } \\
\text { and integration, ending up using a } \\
\text { combination of both. (L8) }\end{array}$ \\
\hline Limits & 7 & $\begin{array}{l}\text { said if } a_{n}<=b_{n} \text { and } a_{n} \text { and } b_{n} \\
\text { have same limit, then there is a } \\
\text { sequence } c_{n} \text { with } a_{n} \leq b_{n} \leq c_{n} \text {. } \\
\text {... didn't really understand ... } \\
\text { squeeze theorem (L24) }\end{array}$ & 0 & \\
\hline Linear algebra & 8 & $\begin{array}{l}\text { Matrix multiplication as } \\
\text { performing transformation in } \\
\text { geometric plane. (L30) }\end{array}$ & 8 & $\begin{array}{l}\text { Gaussian elimination - getting the } \\
\text { various steps in the right order, } \\
\text { and doing the arithmetic (L21) }\end{array}$ \\
\hline $\begin{array}{l}\text { Probability and } \\
\text { statistics }\end{array}$ & 5 & $\begin{array}{l}\text { Identifying which hypothesis test } \\
\text { is appropriate for ... data. (L29) }\end{array}$ & 2 & $\begin{array}{l}\text { Calculating the mean and standard } \\
\text { deviation of a frequency table. } \\
\text { (L23) }\end{array}$ \\
\hline Fractions & 7 & $\begin{array}{l}\text { poor understanding of basic skills } \\
\text { involving equivalent fractions, } \\
\text { common denominator etc. } \\
\text { (L26) }\end{array}$ & 9 & $\begin{array}{l}\text { how to set up a partial fraction } \\
\text { decomposition correctly (L24) }\end{array}$ \\
\hline Word problems & 0 & & 4 & $\begin{array}{l}\text { Converting statements like ' } n \text { is even' } \\
\text { into an equation ( } \mathrm{L} 1)\end{array}$ \\
\hline Trig & 4 & $\begin{array}{l}\text { radians was the most difficult } \\
\text { concept .... students } \\
\text { understood } 60 \text { degrees but had } \\
\text { difficulty with representation } \\
\text { of radians. (L13) }\end{array}$ & 6 & $\begin{array}{l}\text { expressing } \sin (3 x) \text { in terms of } \sin (x) \text {. } \\
\text { (L19) }\end{array}$ \\
\hline
\end{tabular}

\section{Analysis and discussion: themes emerging from the data}

The questionnaires can only inform us as to the perception of both students and lecturers in relation to the difficulty of certain topics within the first-year service mathematics curriculum; they do not provide a measure of student ability. The majority of students' answers to the Likert scale questions which asked them to rank their ability to 'Understand' and 'Do' certain topics (Figure 1) were in the SA (44\%) and A (33\%) categories, with 15\% of responses $\mathrm{N}$ and only $7 \%$ and $1 \%$ in the $\mathrm{D}$ and $\mathrm{SD}$ categories. It is possible that students did not perceive that they had problems with the question types presented, or perhaps they were unwilling to rate their own mathematical ability poorly. Gonyea [21] found upward bias in institutional self-reported data. There, are also studies which have shown that students' self-rating of their abilities can be an effective measure of the learning outcomes they have achieved [22,23]. However, once the responses to the open questions were analyzed, 


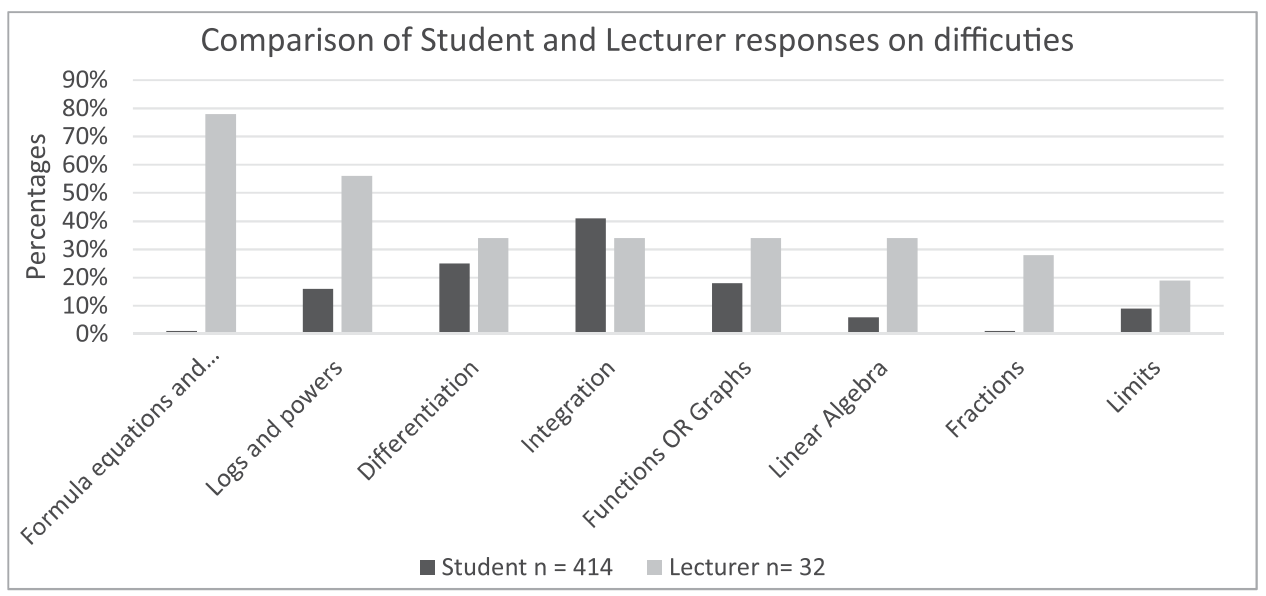

Figure 7. Comparison of the percentage of respondents identifying difficult topics between the student open question on 'Topics Caused Difficulty' and lecturers' open questions on difficult concepts and procedures.

it became clear that the majority of students had identified at least one problematic topic (Figure 2).

\subsection{Comparison between lecturer and students responses}

A comparison of the student and the lecturer responses showed that both differences and similarities existed between the topics identified by each group, as shown in Figure 7.

Basic algebra (formula, equations and symbols) was the most reported topic by lecturers and yet was rarely mentioned by the students. Students and lecturers both identified problems with differentiation and integration. These particular similarities and differences are further discussed below.

\subsubsection{Basic algebra: formula equations and symbols}

Twenty-five (78\%) of the lecturers reported that students had problems in basic algebra such as formula manipulation and solving equations. This was in stark contrast to the responses of students, where less than $4 \%$ of students reported problems in Likert questions in this area (Q1, Q2, Q3, Q7 and Q8 of Figure 1), and only 10 students $(<1 \%)$ reported problems of this nature in the open questions. On the other hand, over half the students (52\%) indicated that they found algebra, or topics within algebra, relatively easy (Figure 6). Lecturers reported that students had difficulty understanding the concept of an equation:

Fundamentally, students don't seem to understand what an equation is: for them $=$ is what you press on the calculator to obtain 'the answer'. The idea that = relates two things that may look different but are equal in value is alien to many students. They don't join the steps in a calculation with $=$ (or $=>$ in the case of a chain of assertions) because they don't seem to have a clear understanding of how they relate to each other. (L11)

Yet many students specifically identified equations as easy, for example: 'I like quadratic equations, most algebra ..., they are easy to follow step by step' (S56). This finding is 
consistent with international studies. Lecturers in the USQ study [5] considered their students were underprepared in algebra, whereas students generally considered they were adequately prepared. In response to a question on whether their students had the ability to 'solve equations', the lecturers in USQ found their students' ability poor.

\subsubsection{Integration and differentiation}

Integration and differentiation were identified as problematic by both students and lecturers (see Figure 7), although students also identified calculus in the 'Easiest Topics' where it was the second most reported topic (Figure 6). However, analysis of these responses showed that students often qualified their answers. For example, one student identified differentiation and integration as an 'Easiest Topic' 'when I know which method to use' (S35). Another student qualified their response by stating that 'I found ...basic differentiation to be the easiest' (S216). Similarly, over 30\% of both lecturers and students in the Huidubro et al. [7] study reported problems with calculus. However, the lecturers in the Wandel et al. [5] study considered students had problems with calculus whereas the students did not.

Students were not asked about integration in the Likert questions, as it was not on the OL LC curriculum. Forty-one percentage of students and $34 \%$ of lecturers identified integration as a problematic topic (Figure 7). Integration is the only topic identified by a greater percentage of students than lecturers. Some of the students had only just encountered integration in first-year mathematics, which may explain why it was the most reported in the open question on 'topics causing difficulty'. Eight percentage of students commented that they had difficulty with topics that they had not previously covered, such as integration and L9 identified that students have difficulty with integration. Wandel et al. [5] also found that students who had covered calculus, incorporating derivatives and integration, in secondary school were more confident in their ability in calculus in their first semester in college.

Many (51) students specifically stated that they did not have difficulty with basic integration but with more complicated integration. The lecturers often gave more insight into what the students likely referred to as complicated integration, such as 'Calculating areas under a graph by integration - more complicated cases involving e.g. cubics where part of the area is negative' (L19). In a similar vein, Mahir [19] found that students had greater difficulty applying procedures when the integration questions did not contain routine manipulations.

Thirty-four percentage of lecturers found that students had problems with differentiation. In the student open responses, $25 \%$ of the respondents reported having problems with differentiation (Figure 7). However, in responding to the Likert scale questions, few students reported problems with basic differentiation and applying rules (between 1.38\% and $8.47 \%$ either disagreed or strongly disagreed with Q17 to Q20, Figure 1). This may be attributed in part to the way the Likert scale questions on differentiation were presented and is one possible limitation of the study: students were informed within each question which differentiation rule applied and an example was given (see Q17, 18 and 19 of Appendix A). This is perhaps best illustrated by one particular student who agreed that they could both 'Understand' and 'Do' all the questions associated with differentiation in the questionnaire, yet commented in the open question: 'Product/Quotient/Chain rule, have difficulty remembering which to use' (S321).

Incorrect reporting of problems with differentiation may also have occurred because students may not have recognized where they had problems, e.g. a problem with differentiation could actually be a problem with logs, partial fractions or functions. This idea was 
suggested by the lecturers. For example, L26 said ' ... most students will have a good idea about the rules for differentiation, many will make mistakes on even basic skills such as multiplying out numerator terms in quotient rule. Galbraith and Hanes [24] made a similar observation, when they found that the engineering students did not make connections between calculus, algebraic and graphical properties.

\subsection{Understanding and doing: concepts and procedures}

In this study we focused on determining student and lecturer perceptions on students' conceptual understanding and procedural fluency. Statistical analysis of the Likert questions indicated that students generally perceived they could 'Understand' rather than 'Do' the question types (chi-squared test, $\mathrm{p}<0.01$ ), with the exception of linear equations, logs and differentiation. In stark contrast, 17 (53\%) of the lecturers specifically identified that their students' problems stemmed from a lack of understanding, for example:

.... anything that requires a real understanding or intellectual thought process. .., unless the students have a model solution or a 'recipe'... - there appears to be no ability to intellectually break a problem down... and work through it from first principles. (L10)

This sentiment is echoed by another lecturer who said that the students were able to solve problems by following methods but 'they often didn't understand the underlying mathematics' (L24). One of the lecturers may have a partial explanation for why students rate their ability to 'Understand' higher than 'Do' when they said 'just because you saw it before does not mean that you understand it' (L15).

Four lecturers referred to students' struggle starting problems and how, if presented with a template, students will do a lot better. L15 said that students 'find it difficult to take the first step when tackling a problem' and L12 found that 'students achieved the correct result more often' when they were given a template of how to lay out the solution. There was little difference between the number of students who identified whether it was the 'Ideas' or the 'Methods' that caused the problem, except in integration and differentiation (Table 2). More students identified the methods of integration and differentiation as problematic. For example a student said: ' ... I feel like I can understand the ideas in these topics but I find the method for solving problems is confusing' (S84). Students tended to get mixed up between which method they should use, with a variety of comments on this such as ' ... Deciding the correct method to use and getting topics muddled up was an issue' (S325). This was also recognized by the lecturers: L8 said that their students were ' ...Mixing up rules for differentiation and integration, ending up using a combination of both. To some extent, this concurs with the fact that student responses to the Likert questions (Q18 and Q19) on applying the product and quotient rules in differentiation rules did not distinguish between 'Understand' and 'Do' whereas students considered they could 'Do' basic differentiation (Q17). Engelbrecht et al. [18] found that when a greater emphasis was put on conceptual teaching in calculus then students were more confident in their conceptual rather than procedural ability and vice versa. This may also be true for the students questioned in this study or it may be that they do not use the term 'understanding' in the same way as their lecturers. For 
example, S76 said 'When you don't understand how to do a question wolfram gives you an answer to work toward'.

Students rarely qualified what they meant by the 'Idea' causing them problems, though one student commented that the 'Ideas' involved in optimisation caused problems ' .... as I found it hard to visualise the question well enough in order to answer' (S5). Lecturers also commented on students' lack of ability to visualize: L19 found students had problems with vectors because they are not 'picturing them, understanding what they are for'. The idea that students' understanding is enhanced by visualization has been discussed in Engelbrecht et al. [18] where they contend that conceptual approaches to solving tasks require translation between verbal and visual representations.

\subsection{Prior mathematical knowledge}

Mathematical confidence and prior mathematical attainment have been shown to influence students' ability in first-year mathematics $[13,25,26]$. In this section, we will discuss how students' prior attainment in mathematics affected their mathematical confidence and the topics they identified as 'topics causing difficulty'.

\subsubsection{Leaving certificate background}

Students who had completed HL mathematics had greater confidence in their ability to both 'Understand' and 'Do' the questions. They reported fewer problems than OL students in the Likert analysis (chi-squared test, $\mathrm{p}<0.00001$ ).

\subsubsection{Identifying particular problematic topics}

In the Likert questionnaire, almost $20 \%$ of OL students disagreed or strongly disagreed that they could both 'Understand' and 'Do' the question types on logs and exponents (Q5 and Q6). In the open questions, significantly more students who had taken OL mathematics identified logs and powers as 'topics causing difficulty' (chi-squared test, $p=0.001$ ). One lecturer specifically identified OL students' difficulties with this topic: 'Recognising 'new' maths functions such as exponent and log (particularly Ordinary Leaving Certificate students)' (L30). Students who had taken OL mathematics may not have encountered logs and powers to the same extent as those who had taken HL. Tariq [14] conjectured that the fact that many students had problems with logs may have been due to the lack of logs as a topic on some of the lower level secondary mathematics curriculum in the UK.

Statistically (chi-squared test, $p=0.027$ ) more students who had taken HL mathematics identified integration as a 'topic causing difficulty'. This may be because students who had taken HL mathematics were more likely to have been registered on undergraduate programmes that had integration on the first-year mathematics curriculum.

\subsubsection{Student and lecturer reference to prior knowledge in open questions}

Thirty-nine $(8 \%)$ of students mentioned that they either found topics easy or difficult depending on whether they had covered them previously (all of these responses refer to LC mathematics). Kajander and Lovric [27] found that students often refer to difficulties associated with material they had not previously covered. It is well documented that students need to overcome the 'fear of new' when transitioning to higher level education [10]. It has 
Table 4. Number of students who identified particular reasons as to how prior mathematics knowledge affects their ability to understand and sample responses $(n=39)$.

\begin{tabular}{lcc}
\hline $\begin{array}{l}\text { Reason students struggles due to prior } \\
\text { mathematics knowledge }\end{array}$ & $\begin{array}{c}\text { \# of } \\
\text { students }\end{array}$ & \multicolumn{1}{c}{ Sample response } \\
\hline $\begin{array}{l}\text { Topics not covered by the leaving certificate } \\
\begin{array}{c}\text { A lack of understanding from the leaving } \\
\text { certificate }\end{array}\end{array}$ & 11 & $\begin{array}{c}\text { Integration (not done in leaving certificate) ... (S2) } \\
\text { Limits! Felt I had no basic understanding from leaving } \\
\text { cert ... (S147) }\end{array}$ \\
$\begin{array}{l}\text { Applying topics to new examples } \\
\text { The different methods used in leaving certificate }\end{array}$ & 5 & $\begin{array}{c}\text { similar questions ... (S167) } \\
\text { Inequalities (method as it was too different to the } \\
\text { method we used in school)..... (S146) }\end{array}$ \\
\hline
\end{tabular}

been shown that students do better when they have already encountered the mathematical content that enables them build the required mathematical skills [4]. Student responses which included the effect of prior mathematical knowledge on their struggles with mathematical topics were analyzed, and the categories which emerged are outlined in Table 4.

Five of the lecturers referred to the poor state of the students' prior mathematics knowledge, with L24 observing that:

...their skills in mastering school mathematics is very poor. The following are examples I saw frequently: $\left(1+x^{2}\right)^{7}=1+x^{14}, \frac{1}{x+3}=\frac{1}{x}+\frac{1}{3}$, and $\left(x^{\frac{3}{2}}\right)^{2}=x^{\frac{9}{4}}$. With such underlying gaps it is very hard to master a first year unit. (L24)

\section{Conclusion}

In this paper we examined and compared the responses to surveys completed separately by students and lecturers. In general, students were optimistic about their ability to complete question types that they were likely to have encountered in first-year undergraduate mathematics modules. Students who had taken OL mathematics at LC were less optimistic than those who had taken HL. Similar results were found in Australia [4-6], Spain [7] and the UK [16]. However, it has been shown that in some cultures and countries there are cultural differences in university students' confidence in their educational ability [28]. In answer to the first research question we found that the most problematic topics identified by students were integration, differentiation, functions, logs and limits. The second research question aimed to identify whether students considered the concept or procedure of the topic caused them difficulty. Students rated their ability to Understand higher than their ability to Do the question types and considered the methods of calculus caused them more problems than the ideas. Students in this survey considered that procedural problems caused them more difficulty than conceptual. While this was somewhat surprising Engelbrecht et al. [18] similarly found that engineering students rated their ability to do conceptual question types higher than that of procedural question types. In contrast and in response to the final research question, lecturers were most concerned about students' lack of ability in some basic algebra such as formula manipulation, solving equations and fractions. Lecturers found that many of the problems students have with more advanced topics are related to a lack of these basic skills. Many lecturers stated that their students did not understand basic mathematical concepts.

There was some agreement between students and lecturers about students' problems with calculus procedures and their inability to manipulate and use logs. Students who had taken OL mathematics found logs particularly problematic. 
There are some limitations to the results discussed; the phrasing of the Likert questions on differentiation enabled students to identify which rule applied to a particular problem, hence they may not have taken into account how difficult they found it to identify the required rules. In addition, students may not have the same definition of Understand and Do, Methods and Ideas as the lecturers. Students sometimes considered that they lacked understanding of a topic when they were perhaps unable to complete a procedural question. Comparison with the lecturers' responses on Concepts and Procedures may need further study.

There have been a number of initiatives implemented to address the gap between students' mathematical ability on entering higher education and the skills they require in order to succeed in first year undergraduate mathematics modules (for example, Mathematics Learning Support [29]). In addition, many institutes have introduced diagnostic testing in order to identify and inform students of their particular gaps in skill [30]. However, this survey indicates that lecturers recognize that students have fundamental problems in understanding of mathematics that students themselves are not aware of. In order to address this need, lecturers should incorporate material in their syllabi that will help students develop understanding such as interactive mathematical tasks specifically designed to improve understanding. Additionally students need to be informed of their lack of understanding through formative assessments that give immediate feedback such as the use of audience response systems.

\section{Note}

1. The project team members contributed to the development, distribution and gathering of the questionnaire data reported on in this paper. Details of this project are available on: http://ims.teachingandlearning.ie/about/.

\section{Disclosure statement}

No potential conflict of interest was reported by the authors.

\section{Funding}

This work was supported by the National Forum for the Enhancement of Teaching and Learning in Ireland [grant number 659].

\section{ORCID}

Caitríona Ní Shé $\odot$ http://orcid.org/0000-0002-6592-0276

Eabhnat Ní Fhloinn @i http://orcid.org/0000-0002-3840-2115

\section{References}

[1] Gill O, O'Donoghue J. Justifying the existence of mathematics learning support: measuring the effectiveness of a mathematics learning centre. In: O’Donoghue J, Maguire T, editors. The Changing Face of Adults Mathematics Education: Learning from the Past, Planning for the Future: Proceedings of the 14th Annual International Conference on Adults Learning Mathematics (ALM); Limerick (Ireland): ALM; 2007. p. 154-163. 
[2] Lawson D, Croft T, Waller D. Mathematics support past, present and future. Innov Pract Res Eng Educ. 2012;1:1-9.

[3] Organisation for Economic Cooperation and Development (OECD). Higher Education to 2030. Higher Educ; 2009; [cited 2016 July 8]. Available from: http://www.oecdilibrary.org/education/higher-education-to-2030-volume-2-globalisation_9789264075375-en

[4] Dalby T, Robinson C, Abdulla S, et al. Students' mathematical preparation Part B : Students' perceptions. In: Ryland L, Loch T, King D, editors. Lighthouse Delta 2013: The 9th Delta Conference on Teaching and Learning of Undergraduate Mathematics and Statistics; Kiama (Australia): The University of Western Sydney, School of Computing, Engineering and Mathematics; 2013. p. 30-39.

[5] Wandel AP, Robinson C, Abdulla S, et al. Students' mathematical preparation: differences in staff and student perceptions. Int J Innov Sci Math Educ. 2015;23(1):82-93.

[6] Galligan L, Wandel A, Pigozzo R. Students ' mathematical preparation Part A : lecturers ' perceptions. In: King D, Loch B, Rylands L, editors. Lighthouse Delta 2013: The 9th Delta Conference on Teaching and Learning of Undergraduate Mathematics and Statistics; Kiama (Australia): The University of Western Sydney, School of Computing, Engineering and Mathematics; 2013. p. 40-49.

[7] Huidobro JA, Serrano ML. Mathematical background of students beginning engineering degrees. In: I. Candel Torres, L. Gómez Chova, A. López Martínez, editors. International Conference of Education, Research and Innovation; Madrid (Spain): IATED; 2011. p. 4114-4122.

[8] Ní Shé C, Mac an Bhaird C, Ní Fhloinn E, et al. Students' and lecturers' views on mathematics resources. Teach Math Appl. Forthcoming.

[9] Department of Education and Skills. A brief description of the Irish education system; 2005; [cited 2016 July 8]. Available from: http://www.education.ie/en/Publications/EducationReports/A-Brief-Description-of-the-Irish-Education-System.pdf

[10] Clark M, Lovric M. Suggestion for a theoretical model for secondary- tertiary transition in mathematics. Math Educ Res J. 2008;20(2):25-37.

[11] Gueudet G. Investigating the secondary - tertiary transition. Educ Stud Math. 2008;67:237254.

[12] Gill O, O'Donoghue J, Faulkner F, et al. Trends in performance of science and technology students (1997-2008) in Ireland. Int J Math Educ Sci Technol. 2010;41(3):323-339.

[13] Loughlin WA, Watters DJ, Brown CL, et al. Snapshot of mathematical background demographics of a broad cohort of first year chemistry science students. Int J Innov Sci Math Educ. 2015;23(1):21-36.

[14] Tariq VN. A decline in numeracy skills among bioscience undergraduates. J Biol Educ. 2002;36(2):76-83.

[15] Watters DJ, Watters JJ. Student Understanding of pH. Biochem Mol Biol Educ. 2006;34(4):278284.

[16] Tariq VN. Defining the problem: mathematical errors and misconceptions exhibited by firstyear bioscience undergraduates. Int J Math Educ Sci Technol. 2008;39(7):889-904.

[17] Engelbrecht J, Harding A, Potgieter M. Undergraduate students' performance and confidence in procedural and conceptual mathematics. Int J Math Educ Sci Technol. 2005;36(7): 701-712.

[18] Engelbrecht J, Bergsten C, Kagesten O. Conceptual and procedural approaches to mathematics in the engineering curriculum: student conceptions and performance. J Eng Educ. 2012;101(1):138-162.

[19] Mahir N. Conceptual and procedural performance of undergraduate students in integration. Int J Math Educ Sci Technol. 2009;40(2):201-211.

[20] Thomas DR. A general inductive approach for analyzing qualitative evaluation data. Am J Eval. 2006;27(2):237-246.

[21] Gonyea RM. Self-reported data in institutional research: review and recommendations. New Dir Instutional Res. 2005;2005(127):73-89. 
[22] Lee CS, McNeill NJ, Douglas EP, et al. Indispensable resource? A phenomenological study of textbook use in engineering problem solving. J Eng Educ. 2013;102(2):269-288.

[23] Douglas AJ, Thomson G, Zhao C-M. The learning outcomes race: the value of self-reported gains in large research universities. High Educ. 2012;64:317-335.

[24] Galbraith P, Haines C. Conceptual mis (understandings) of beginning undergraduates. Int J Math Educ Sci Technol. 2000;31(5):651-678.

[25] Allen J, Robbins SB. Prediction of college major persistence based on vocational interests, academic preparation, and first-year academic performance. Res High Educ. 2008;49(1):62-79.

[26] Wang X. Baccalaureate attainment and college persistence of community college transfer students at four-year institutions. Res High Educ. 2009;50(6):570-588.

[27] Kajander A, Lovric M. Transition from secondary to tertiary mathematics: McMaster University experience. Int J Math Educ Sci Technol. 2005;36(2-3):149-160.

[28] Lundeberg MA, Fox PW, Brown AC, et al. Cultural influences on confidence: country and gender. J Educ Psychol. 2000;92(1):152-159.

[29] O'Sullivan C, Mac an Bhaird C, Fitzmaurice O, et al. An Irish mathematics learning support network (IMLSN) report on student evaluation on of mathematics learning support: insights from a large scale multi-institutional survey. Ireland: NCE-MSTL; 2015.

[30] Ní Fhloinn E, Mac an Bhaird C, Nolan B. University students' perspectives on diagnostic testing in mathematics. Int J Math Educ Sci Technol. 2014;45(1):58-74.

\section{Appendices}

\section{Appendix 1. Student questionnaire}

\section{List of the 23 question types students were asked to rate}

Q1: Systems of Linear Equations 2 variables

Q2: Systems of Linear Equations 3 variables

Q3: Rearranging Formula

Q4: Powers - using laws of indices

Q5: Logs - using the laws of logarithms to simplify expressions

Q6: Using the connections between logs and exponents

Q7: Solving inequalities

Q8: Solving quadratic equations

Q9: Graphing basic functions

Q10: Interpreting graphs of basic functions

Q11: Algebraic fractions

Q12: Dealing with percentage change

Q13: Finding limits of functions using graphs

Q14: Finding limits of functions using rules of limits

Q15: Finding and graphing the tangent to the curve

Q16: Deciding whether a function is continuous or not

Q17: Basic Differentiation

Q18: Differentiation: the product rule

Q19: Differentiation: the quotient rule

Q20: Differentiation: the chain rule

Q21: Finding stationary points

Q22: Optimization ( $\mathrm{max} / \mathrm{min}$ ) problems

Q23: Graph sketching using derivatives

Question 14 format and an example of this question type 


\section{Finding limits of functions using rules of limits}

Strongly agree Agree Neutral Disagree Strongly disagree

I understand the ideas in questions like this.

I am able to do questions like this.

\section{Finding limits of functions using rules of limits}

Example: Use the rules of limits to evaluate

$$
\lim _{x \rightarrow 2} \frac{3 x^{2}-4 x+9}{x+5}
$$

\section{Open questions}

1. What topics in first year mathematics caused you most difficulty? (Feel free to include topics that are not on the list above.) Please indicate whether it was the methods or the ideas involved that made the topic difficult for you.

2. What topics in first-year mathematics did you find most easy?

3. Please list any resources that you have found helpful for dealing with first-year mathematics topics.

(Please give as much detail (e.g. web address) as possible.)

Books:

Handouts:

Videos:

Websites:

Other (please specify):

If possible, please indicate why the resources listed above were useful.

4. Are there any gaps in the resources available? Please explain.

5 . Have you any advice on the resources you would like us to develop?

6. How should these resources be made available?

Print-based:

Videos:

Websites:

Other (please specify):

7. Any other comments

\section{Appendix 2. Lecturer survey questions}

1. Institution name

2. Department

3. Please list the names of first-year service mathematics modules that you teach or have taught recently and the student groups/programmes involved.

4. What concepts in the first-year curriculum do your students find most difficult to understand?

5. What procedures and tasks in the first-year curriculum cause most difficulty for your students? 
6. Please list any resources that you have found helpful to aid students with the difficulties outlined above.

7. If possible, please indicate why the resources listed above were useful.

8. Are there any gaps in the resources available? Please explain.

9. Have you any advice on the resources you would like us to develop?

10. How should these resources be made available?

11. Do you agree to participate in this study? 